\title{
MicroRNA-590-3p enhances the radioresistance in glioblastoma cells by targeting LRIG1
}

\author{
LONG CHEN $^{1,2}$, WENHUA WANG ${ }^{2}$, SHENGQIANG ZHU ${ }^{2}$, XUEGANG JIN ${ }^{2}$, \\ JIAN WANG $^{2}$, JIANFANG ZHU ${ }^{2}$ and YOUXIN ZHOU ${ }^{1}$ \\ ${ }^{1}$ Department of Neurosurgery \& Brain and Nerve Research Laboratory, \\ The First Affiliated Hospital of Soochow University, Suzhou, Jiangsu 215006; ${ }^{2}$ Department of Neurosurgery, \\ The Affiliated Hospital of Nanjing University of Chinese Medicine, Kunshan, Jiangsu 215300, P.R. China
}

Received August 14, 2015; Accepted January 6, 2017

DOI: 10.3892/etm.2017.4697

\begin{abstract}
RNA (miR)-590 has been found to serve potential roles in cancer development; however, the expression and function of miR-590 in human gliomas remains to be elucidated. The present study aimed to investigate the expression of miR-590 in human glioma tissues and radioresistant human glioblastoma cells (U251R), and to determine the effect and related molecular mechanism of miR-590-3p on the radiosensitivity of $\mathrm{U} 251 \mathrm{R}$ cells in vitro. The results from reverse transcription-quantitative polymerase chain reaction indicated that miR-590-3p was upregulated in human glioma tissues and radioresistant human glioblastoma cells, and that miR-590-3p expression was higher in high grade than in low grade gliomas. In vitro experiments revealed that the miR-590-3p inhibitor enhanced the radiosensitivity of U251R cells by suppressing cell viability, decreasing colony formation capacity and increasing cell apoptosis rate, as demonstrated by MTT, colony formation and flow cytometry analyses. A luciferase reporter assay demonstrated that leucine-rich repeats and immunoglobulin-like domains protein 1 (LRIG1) was a direct target of miR-590-3p. Furthermore, it was demonstrated that the effect of miR-590-3p suppression on cell viability, colony formation capacity and cell apoptosis rate was attenuated by the knockdown of LRIG1 in the U251R cells. In conclusion, the present study revealed that miR-590-3p was upregulated in human glioma tissues and radioresistant human glioblastoma cells, and miR-590-3p contributes to the radioresistance of human glioblastoma cells by directly targeting LRIG1. These findings may provide potential therapeutic strategies to prevent radioresistance in human gliomas.
\end{abstract}

Correspondence to: Professor Youxin Zhou, Department of Neurosurgery \& Brain and Nerve Research Laboratory, The First Affiliated Hospital of Soochow University, 188 Shizi Street, Suzhou, Jiangsu 215006, P.R. China

E-mail: youxin_zh@tom.com

Key words: microRNA-590-3p, glioblastoma, radiosensitivity, leucine-rich repeats and immunoglobulin-like domains protein 1

\section{Introduction}

Gliomas account for approximately $30 \%$ of all brain and central nervous system tumors (1), and glioblastoma is the most common and malignant glioma (2). Despite advances in surgical resection, radiotherapy, chemotherapy and other therapeutic approaches, including immune and gene therapy, the prognosis for patients with glioblastoma remains poor (3-7). A previous study demonstrated that the median survival time of patients with glioblastoma was 4.9 months following diagnosis (8). Resistance of glioblastoma cells to irradiation therapy is a major obstacle in the treatment of human glioblastoma (9). Therefore, it is important to elucidate the mechanisms underlying this resistance to irradiation therapy and identify efficient radiosensitizers.

MicroRNAs (miRNAs or miRs) are a class of small, functional and non-coding RNAs that regulate the expression of target mRNAs at the post-transcriptional level $(10,11)$. The altered expression of specific miRNAs has been implicated to serve important roles in the initiation and progression of tumors, including tumor radiation resistance $(12,13)$.

The human miR-590 family has two mature members, miR-590-3p and miR-590-5p. It has been demonstrated that miR-590 is associated with the development of various types of cancer, including breast cancer (14), cervical cancer (15), clear cell renal carcinoma (16) and hepatocellular carcinoma (17). To the best of our knowledge, the present study is the first to investigate the expression and function of miR-590 in human gliomas.

Leucine-rich repeats and immunoglobulin-like domains protein 1 (LRIG1) is considered to be a tumor suppressor in various types of cancer and is frequently downregulated in gliomas (18-21). Therefore, the present study elucidated whether LRIG1 is a novel direct target by which miR-590-3p exerts its effect on radiosensitivity, as LRIG1 is predicted to be a target of miR-590-3p (http://www.microrna.org/microrna/home.do) and the expression of LRIG1 is associated with radiosensitivity in human glioblastoma (22). Furthermore, the levels of miR-590-3p and miR-590-5p expression in human glioma tissues and radioresistant human glioblastoma cells (U251R) were evaluated and the effect of miR-590-3p on the radiosensitivity of U251R cells in vitro was investigated. 


\section{Materials and methods}

Tissue collection. The collection of tissue samples was approved by the Ethics Committee of The First Affiliated Hospital of Soochow University (Suzhou, China). All participants provided written informed consent prior to enrollment. Glioma tissue and matched adjacent normal tissue were collected from 35 patients with glioma who underwent surgery at The First Affiliated Hospital of Soochow University between May 2013 and March 2015, including 5 patients with grade I, 12 patients with grade II, 6 patients with grade III and 12 patients with grade IV. The grades of gliomas were determined according to WHO criteria (23). None of these patients had received radiotherapy or chemotherapy prior to surgery.

Cell culture and irradiation treatment. U251 and HEK293 cells were purchased from the cell bank of the Type Culture Collection of the Chinese Academy of Sciences (Shanghai, China), and were cultured in Dulbecco's modified Eagle's medium (DMEM) with 10\% fetal bovine serum and $2 \mathrm{mM}$ L-glutamine (all Gibco; Thermo Fisher Scientific, Inc., Waltham, MA, USA). Cells were maintained at $37^{\circ} \mathrm{C}$ in an atmosphere containing $5 \% \mathrm{CO}_{2}$. The U251 cells were then exposed to a series of increasing X-ray doses from 1-10 Gy at a dose rate of $1 \mathrm{~Gy} / \mathrm{min}$ for ten repeats, and the surviving cells were harvested, cultured in DMEM supplemented with $10 \%$ fetal bovine serum and $2 \mathrm{mM} \mathrm{L}$-glutamine at $37^{\circ} \mathrm{C}$ and designated as the radioresistant subline (U251R). U251 and U251R cells were treated with $6 \mathrm{~Gy}$ X-ray radiation $24 \mathrm{~h}$ prior to MTT assay and flow cytometry. For colony formation assay, the U251 and the U251R cells were exposed to 0-8 Gy X-ray radiation.

Cell transfection. Cells were seeded onto six-well plates at $5 \times 10^{4}$ cells/well at $37^{\circ} \mathrm{C}$ overnight until $50 \%$ confluence was reached. A total of $5 \mu 1$ Lipofectamine ${ }^{\circledR} 2000$ (Invitrogen; Thermo Fisher Scientific, Inc.), $10 \mathrm{nM}$ miR-590-3p mimic, $10 \mathrm{nM}$ miR-590-3p inhibitor and $10 \mathrm{nM}$ LRIG1 short interfering (si)RNA (forward, 5'-CCGGUUCUAUUUCAGCUA ATT-3' and reverse, 5'-UUAGCUGAAAUAGAACCGGTT-3'; all from Shanghai GenePharma Co., Ltd., Shanghai, China) were diluted in $250 \mu \mathrm{l}$ Opti-MEM I (Invitrogen; Thermo Fisher Scientific, Inc.) separately and incubated at room temperature for $5 \mathrm{~min}$. The mimic/inhibitor or siRNA was subsequently mixed gently with Lipofectamine ${ }^{\circledR} 2000$ and incubated at room temperature for $20 \mathrm{~min}$ to form complexes. The complexes were added to each well and plates were incubated at $37^{\circ} \mathrm{C}$ for $6 \mathrm{~h}$. The medium was subsequently replaced with fresh medium.

Luciferase assay. The wild type or mutant LRIG1 3' untranslated region (UTR; Shenzhen Lvshiyuan Biotechnology Co., Ltd., Shenzhen, China) was cloned into the pmirGLO luciferase reporter vector (Promega Corporation, Madison, WI, USA), and co-transfected with the miR-590-3p mimic or the miR-negative control (NC) (Shanghai GenePharma Co., Ltd., Shanghai, China) into the HEK293 cells using Lipofectamine ${ }^{\circledR} 2000$ (Invitrogen; Thermo Fisher Scientific, Inc.). The pRL-TK Renilla luciferase reporter vector (Promega
Corporation) was transfected into cells as an internal control. At $24 \mathrm{~h}$ following transfection, luciferase activity was measured using a Dual-Luciferase Reporter Assay System (Promega Corporation) following cells lysis with Passive Lysis Buffer included in the Reporter Assay System. Relative luciferase activity was calculated as the ratio of firefly luciferase activity to Renilla luciferase activity.

Reverse transcription-quantitative polymerase chain reaction $(R T-q P C R)$. miRNAs were isolated from the harvested tissues and cultured cells using the miRNeasy Mini kit (Qiagen GmbH, Hilden, Germany) according to the manufacturer's protocols. A total of $1 \mu \mathrm{g}$ RNA was reverse transcribed to cDNA using the First Strand cDNA Synthesis kit (Fermentas, Vilnius, Lithuania). Specific primers for miR-590-3p (forward, 5'-TAATTTTATGTATAAGCT AGT-3' and reverse, 5'-TGGTGTCGTGGAGTCG-3') and miR-590-5p (forward, 5'-TAATTTTATGTATAAGCTAGT-3' and reverse, 5'-TGGTGTCGTGGAGTCG-3') were obtained from Sangon Biotech Co., Ltd. (Shanghai, China). qPCR was performed using the SYBR-Green PCR kit (Applied Biosystems; Thermo Fisher Scientific, Inc.) in an ABI Prism 7900HT Sequence Detection System (Applied Biosystems; Thermo Fisher Scientific, Inc.). The PCR reaction conditions were as follows: 40 cycles at $95^{\circ} \mathrm{C}$ for $30 \mathrm{sec}, 1$ cycle at $59^{\circ} \mathrm{C}$ for $30 \mathrm{sec}$ and $1 \mathrm{cycle}$ at $72^{\circ} \mathrm{C}$ for $30 \mathrm{sec}$. All reactions were repeated three times. The U6 gene was used for the internal control. miR-590-3p and miR-590-5p levels were quantified using the $2^{-\triangle \Delta \mathrm{Cq}}$ method (24).

Western blot analysis. Total protein was extracted from the cultured cells using a Total Protein Extraction kit (Nanjing KeyGen Biotech Co., Ltd., Nanjing, China) and centrifuged at $1,000 \mathrm{x} g$ at room temperature for $10 \mathrm{~min}$. A $10 \%$ SDS-PAGE gel was used to separate total proteins ( $20 \mu \mathrm{g} / \mathrm{lane})$, which was subsequently transferred onto nitrocellulose membranes (EMD Millipore, Billerica, MA, USA) via electroblotting. Following blocking with non-fat milk at $4^{\circ} \mathrm{C}$ overnight, membranes were incubated with the primary rabbit polyclonal LRIG1 antibody (1:400; cat. no. ab36707) and rabbit polyclonal GAPDH antibody (1:1,000; cat. no. ab37168; Abcam, Cambridge, MA, USA) at $37^{\circ} \mathrm{C}$ for $1 \mathrm{~h}$, respectively, followed by incubation with the mouse monoclonal anti-rabbit immunoglobulin horseradish peroxidase-conjugated secondary antibody $(1: 2,000$; cat. no. ab99702; Abcam) at $37^{\circ} \mathrm{C}$ for $1 \mathrm{~h}$. GAPDH antibody was used as a loading control. The signals were detected using a Pierce ${ }^{\mathrm{TM}}$ Fast Western Blot kit with ECL Substrate (Pierce; Thermo Fisher Scientific, Inc.). Band density was quantified using ImageJ 1.48 software (National Institutes of Health, Bethesda, MD, USA). Experiments were repeated three times.

MTT assay. Cells were incubated in 96-well plates at a density of $5 \times 10^{4}$ cells $/ \mathrm{ml}$ and allowed to grow at $37^{\circ} \mathrm{C}$ for 24,48 , 72 and $96 \mathrm{~h}$. A total of $10 \mu \mathrm{l}$ MTT $(0.5 \mathrm{mg} / \mathrm{ml}$; Sigma-Aldrich; Merck KGaA, Darmstadt, Germany) was added to each well and cells were incubated at $37^{\circ} \mathrm{C}$ for another $4 \mathrm{~h}$. Culture medium was subsequently discarded, and $150 \mu$ l dimethylsulfoxide (Sigma-Aldrich; Merck KGaA) was added to each well to dissolve the formazan crystals. Absorbance was measured at $570 \mathrm{~nm}$ using a microplate reader. 


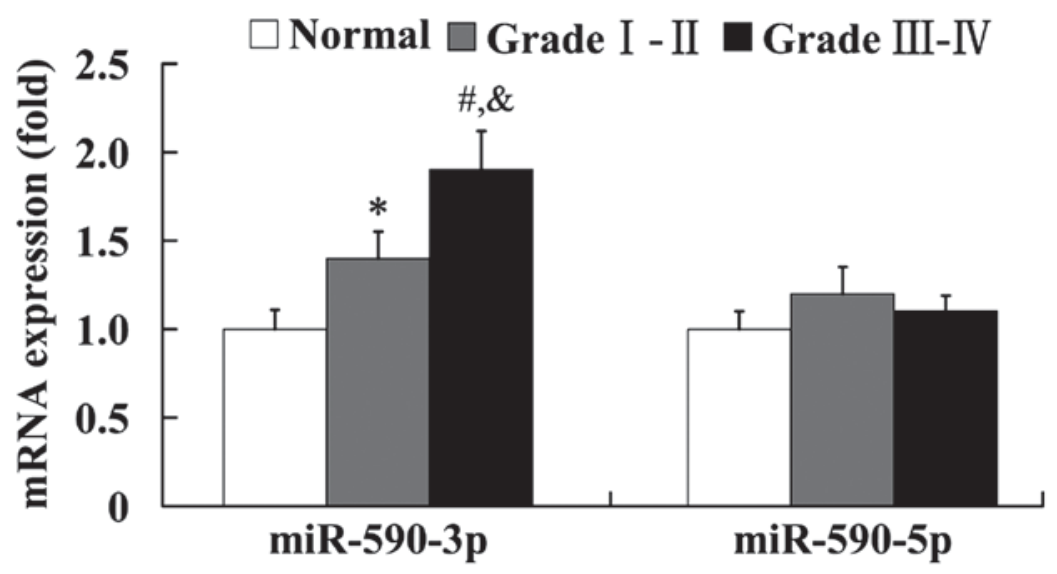

Figure 1. Expression of miR-590 in human glioma tissues. ${ }^{*} \mathrm{P}<0.05,{ }^{\text {}} \mathrm{P}<0.01$ vs. the normal group; ${ }^{\text {}} \mathrm{P}<0.05$ vs. grade I-II gliomas. miR, microRNA.

Flow cytometry. Cell apoptosis rate was determined using the Annexin V-fluorescein isothiocyanate and propidium iodide (PI) Apoptosis assay kit (Nianjin KeyGen Biotech Co., Ltd.) and flow cytometry. A total of $5 \times 10^{5}$ cells/well were seeded into six-well plates and were cultured in DMEM supplemented with $10 \%$ fetal bovine serum and $2 \mathrm{mM} \mathrm{L}$-glutamine. Cells were treated with 6 Gy radiation. Following 24 h, cells were subsequently harvested, washed 3 times with phosphate-buffered saline, and dual-stained with PI and Alexa Fluor 488-Annexin V. The stained cells were analyzed via flow cytometry on a BD Accuri C6 flow cytometer and CFlow Plus software, v1.0.172.9 (BD Biosciences, Franklin Lakes, NJ, USA).

Colony formation assay. Cells were plated in six-well plates at densities of 100, 400, 600, 800 and 1,000 cells/well and were exposed to $0,2,4,6$ and 8 Gy radiation, respectively. Following incubation at $37^{\circ} \mathrm{C}$ for 14 days, the cells were fixed with $4 \%$ paraformaldehyde at room temperature for $15 \mathrm{~min}$ and then stained with $0.5 \%$ crystal violet. Colonies with $>50$ cells were counted under a light microscope.

Statistical analysis. Data are expressed as the mean + standard deviation. SPSS 19.0 software (IBM SPSS, Armonk, NY, USA) was used for statistical analysis. Comparison of data between two groups was performed using the Student's t-test. $\mathrm{P}<0.05$ was considered to indicate a statistically significant difference.

\section{Results}

Expression of miR-590 in human glioma tissues. The expression of miR-590-3p and miR-590-5p in human glioma tissues was examined using RT-qPCR. As shown in Fig. 1, the mRNA level of miR-590-3p was significantly upregulated in the grades I-II and III-IV glioma tissues compared with the normal brain tissues $(\mathrm{P}<0.05$ and $\mathrm{P}<0.01$, respectively). Furthermore, it was found that miR-590-3p expression levels were significantly higher in the high grade gliomas (grades III and IV) than in the low grade gliomas (grades I and II; P<0.05). However, the mRNA level of miR-590-5p did not show any significant difference between the normal and glioma tissues (Fig. 1).
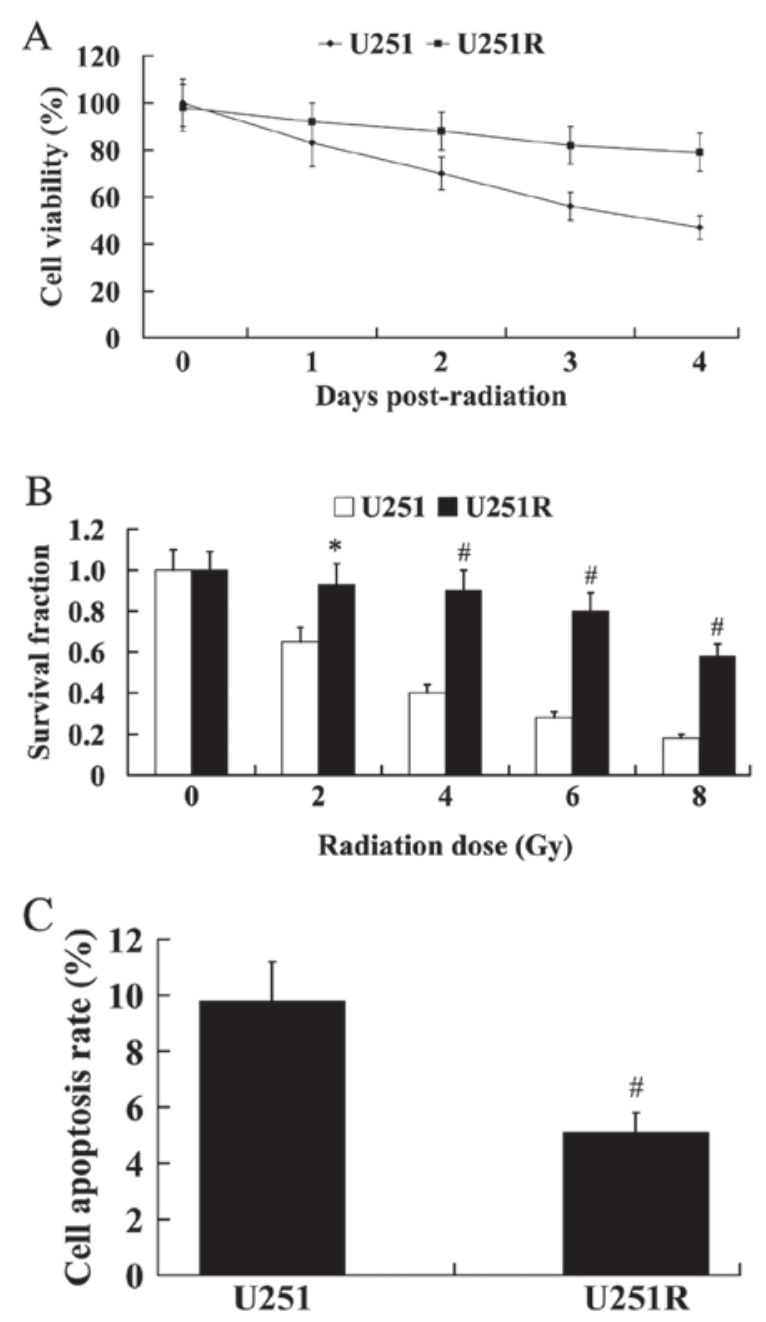

Figure 2. The radiosensitivity of U251 and U251R cells. (A) Cell viability of U251 and U251R cells. (B) Survival fraction of U251 and U251R cells. (C) Cell apoptosis rate of U251 and U251R cells. ${ }^{*} \mathrm{P}<0.05,{ }^{\#} \mathrm{P}<0.01$ vs. U251 cells. U251R, radioresistant U251.

Establishment of U251R glioblastoma cell. As shown in Fig. 2A, the U251R cells exhibited higher cell viability compared with the U251 cells. The results from colony formation assay demonstrated that U251R cells exhibited significantly higher colony formation capacity following irradiation than U251 cells 
A

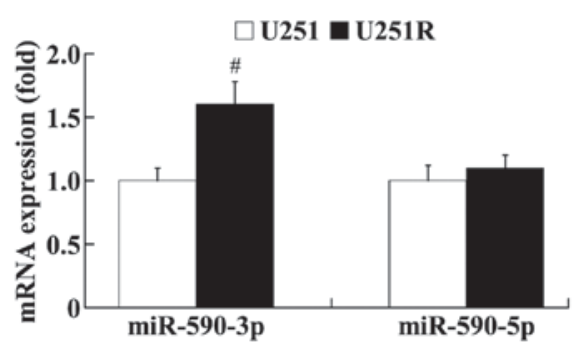

B
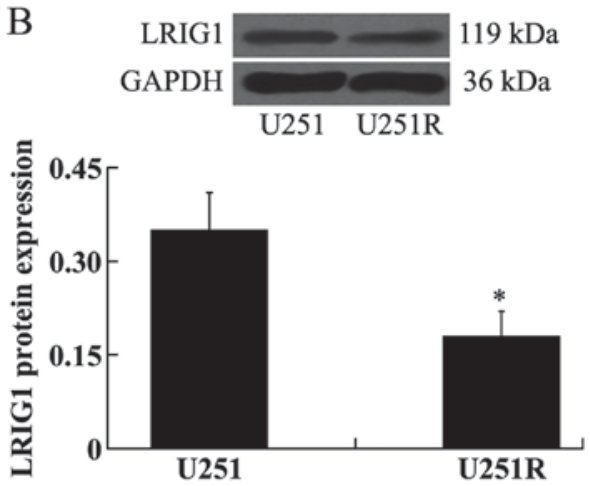

Figure 3. Expression of miR-590 and LRIG1 in U251 and U251R cells. (A) Relative mRNA level of miR-590-3p and miR-590-5p in U251 and U251R cells. (B) Relative protein level of LRIG1 in U251 and U251R cells. ${ }^{\prime} \mathrm{P}<0.05,{ }^{*} \mathrm{P}<0.01$ vs. U251 cells. miR, microRNA; LRIG1, leucine-rich repeats and immunoglobulin-like domains protein 1; U251R, radioresistant U251.

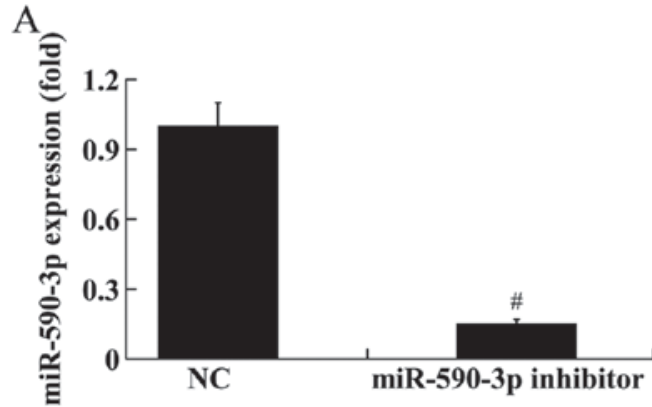

C

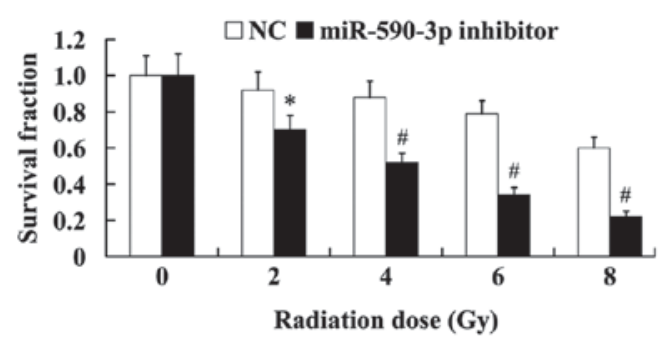

B

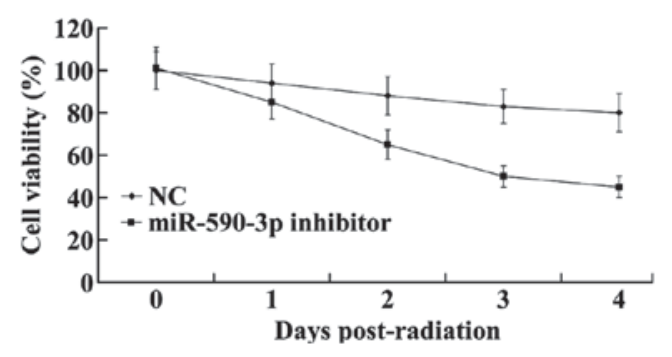

$\mathrm{D}$

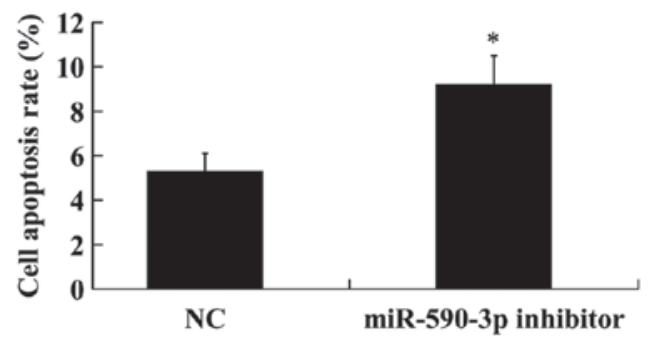

Figure 4. Effect of miR-590-3p on the radiosensitivity of U251R cells. U251R cells were exposed to radiation following transfection with the miR-590-3p inhibitor. (A) Relative mRNA level of miR-590-3p in U251R cells following transfection with the miR-590-3p inhibitor. (B) Cell viability of U251R cells following transfection with the miR-590-3p inhibitor. (C) Survival fraction of U251R cells following transfection with the miR-590-3p inhibitor. (D) Cell apoptosis rate of U251R cells following transfection with the miR-590-3p inhibitor. "P $<0.05,{ }^{\#} \mathrm{P}<0.01$ vs. NC. miR, microRNA; U251R, radioresistant U251; $\mathrm{NC}$, negative control.

(Fig. 2B; $\mathrm{P}<0.05$ at $2 \mathrm{~Gy} ; \mathrm{P}<0.01$ at 4,6 and $8 \mathrm{~Gy}$ ). In addition, U251R cells had a significantly lower cell apoptosis rate than U251 cells following irradiation (Fig. 2C; $\mathrm{P}<0.01$ ).

Expression of miR-590 and LRIG1 in U251R cells. The expression of miR-590-3p, miR-590-5p and LRIG1 in the radioresistant cells U251R was evaluated using RT-qPCR and western blot analysis. The results from RT-qPCR analysis showed that, compared with U251 cells, the expression level of miR-590-3p was significantly increased in the U251R cells $(\mathrm{P}<0.01)$; however, the expression level of miR-590-5p was not significantly different between U251 and U251R cells (Fig. 3A). The results from western blot analysis demonstrated that the expression of LRIG1 protein was significantly downregulated in U251R cells compared with U251 cells (Fig. 3B; $\mathrm{P}<0.05)$.
Effect of miR-590-3p on the radiosensitivity of U251R cells. To investigate the effect of $\mathrm{miR}-590-3 \mathrm{p}$ on the radiosensitivity of U251R cells, the miR-590-3p inhibitor was transfected into the U251R cells, and the cells were exposed to 6 Gy radiation for 24 h. As shown in Fig. 4A, the mRNA level of miR-590-3p in cells transfected with the miR-590-3p inhibitor significantly decreased to $15 \%$ of the control $(\mathrm{P}<0.01)$. The results from MTT assay revealed that the cells transfected with the miR-590-3p inhibitor exhibited markedly decreased cell viability compared with the control (Fig. 4B). Colony formation capacity was also significantly decreased in the cells transfected with the miR-590-3p inhibitor following irradiation, compared with controls (Fig. 4C; $\mathrm{P}<0.05$ at 2 Gy; $\mathrm{P}<0.01$ at 4, 6 and $8 \mathrm{~Gy}$ ). Furthermore, flow cytometry demonstrated that transfection with the miR-590-3p inhibitor significantly increased the cell apoptosis rate (Fig. 4D; $\mathrm{P}<0.05$ ). 


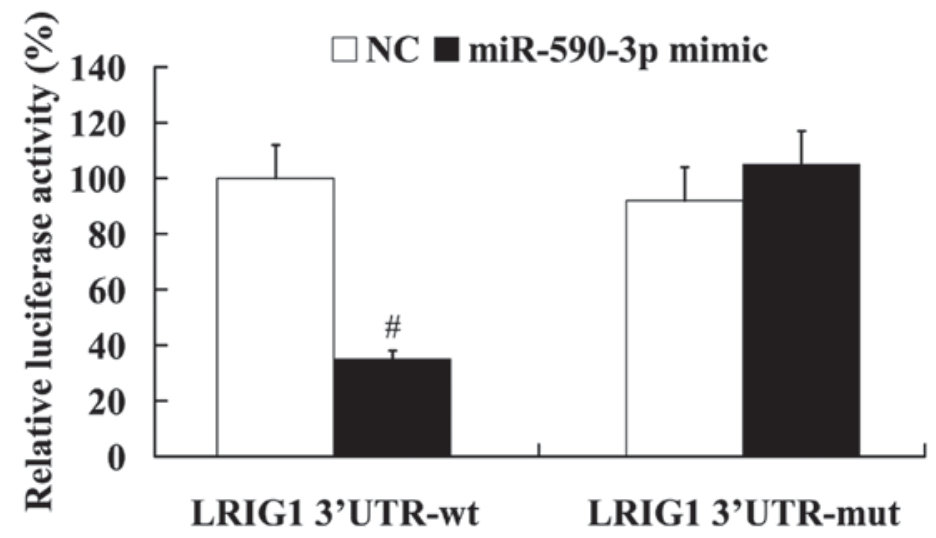

Figure 5. Relative luciferase activity of wt or mut LRIG1 3'UTR in HEK293 cells following co-transfection with the NC or miR-590-3p mimic. "P<0.01 vs. NC. wt, wild type; mut, mutant; LRIG1, leucine-rich repeats and immunoglobulin-like domains protein 1; UTR, untranslated region; NC, negative control; miR, microRNA.

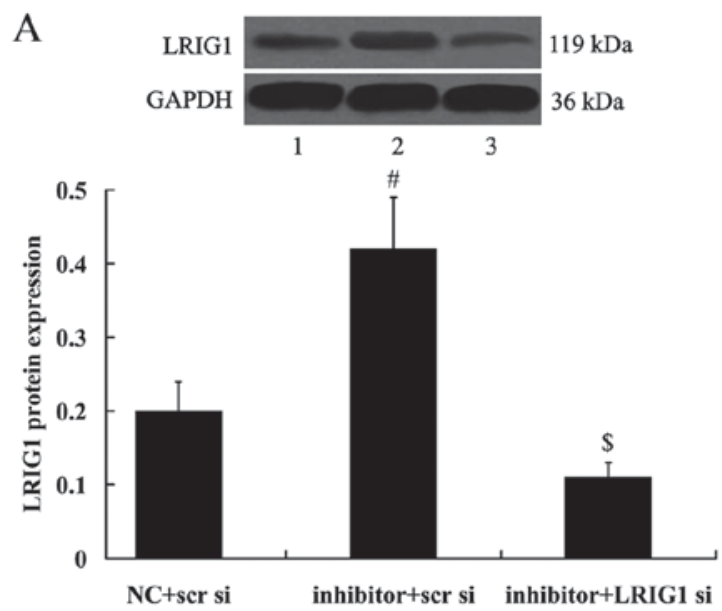

B

C

$\square$ NC+ser si $\square$ Inhibitor+ser si $\square$ Inhibitor+LRIG1 si
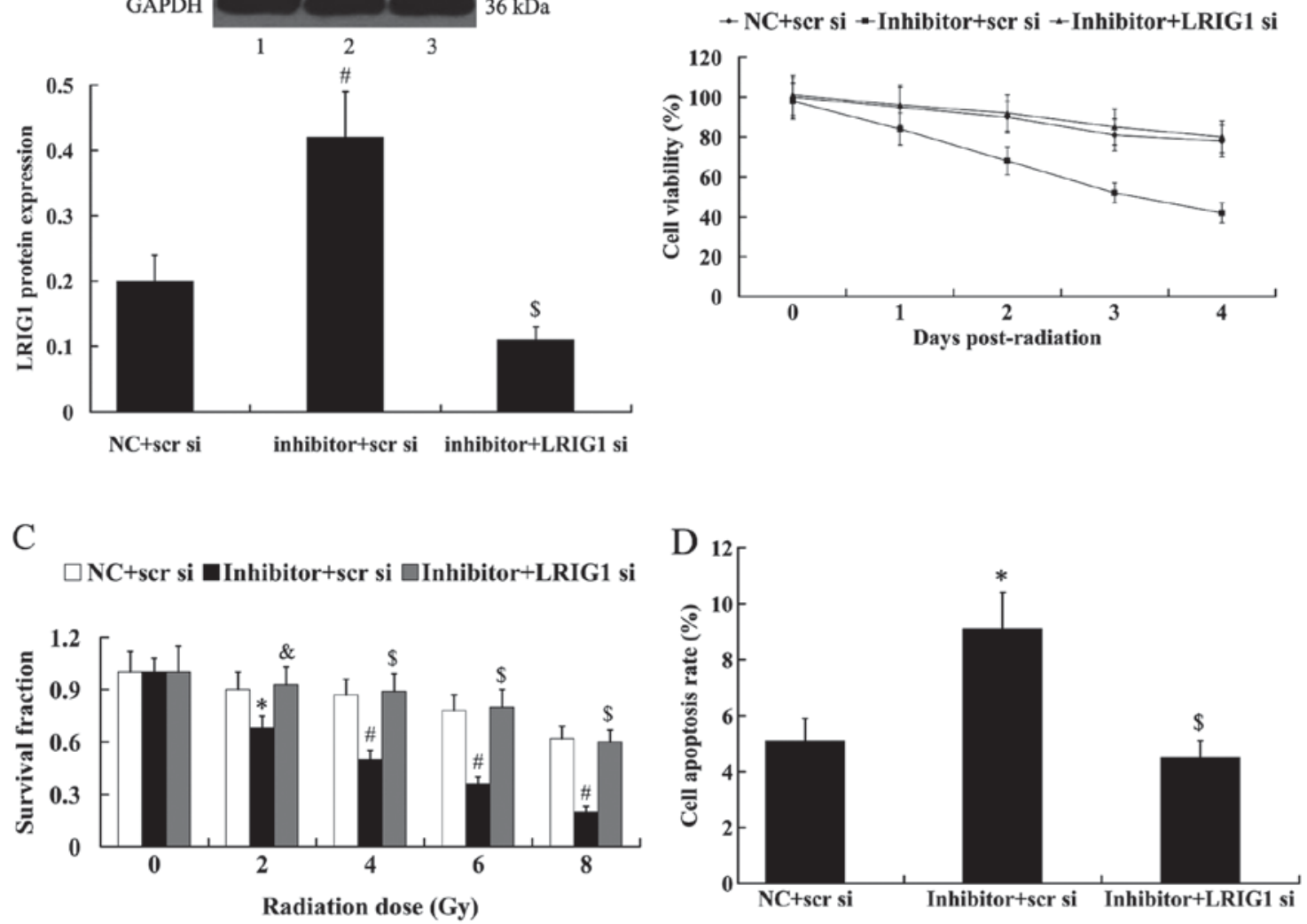

Figure 6. LRIG1 reversed the effect of miR-590-3p on the radiosensitivity of U251R cells. U251R cells were exposed to radiation following transfection. (A) Relative protein level of LRIG1 in U251R cells following transfection with the miR-590-3p inhibitor and LRIG1 siRNA. Lane 1, NC + scr si; lane 2, inhibitor + scr si; lane 3, inhibitor + LRIG1 si. (B) Cell viability of U251R cells following transfection with the miR-590-3p inhibitor and LRIG1 siRNA. (C) Survival fraction of U251R cells following transfection with the miR-590-3p inhibitor and LRIG1 siRNA. (D) Cell apoptosis rate of U251R cells following transfection with the miR-590-3p inhibitor and LRIG1 siRNA. "P $<0.05,{ }^{\#} \mathrm{P}<0.01$ vs. NC + scr si; ${ }^{\circ} \mathrm{P}<0.05,{ }^{\circ} \mathrm{P}<0.01$ vs. inhibitor + scr si. LRIG1, leucine-rich repeats and immunoglobulin-like domains protein 1; miR, microRNA; U251R, radioresistant U251; si, short interfering; NC, negative control; scr, scramble.

LRIG1 is a direct target of miR-590-3p. To elucidate the association between miR-590-3p and LRIG1, the LRIG1 3'UTR containing the wild type or mutant potential target site of miR-590-3p was constructed, and co-transfected with the miR-590-3p mimic into HEK293 cells. The results from the luciferase reporter assay demonstrated that the miR-590-3p mimic significantly decreased the luciferase activity of wild type LRIG1 3'UTR $(\mathrm{P}<0.01)$, whereas the luciferase activity of mutant LRIG1 3'UTR was not significantly affected by the miR-590-3p mimic (Fig. 5).

LRIG1 mediates the effect of miR-590-3p on the radiosensitivity of U251R cells. To identify whether LRIG1 mediates the effect of miR-590-3p on the radiosensitivity of U251R cells, 
LRIG1 siRNA was transfected into U251R cells to knockdown LRIG1, and the cells were exposed to $6 \mathrm{~Gy}$ radiation for $24 \mathrm{~h}$. As shown in Fig. 6A, miR-590-3p inhibitor significantly increased the expression of LRIG1 protein in U251R cells compared with controls $(\mathrm{P}<0.01)$; however, this increased LRIG1 expression was abolished by the transfection of LRIG1 siRNA. The effect of miR-590-3p on the radiosensitivity of U251R cells was significantly attenuated by LRIG1 $(\mathrm{P}<0.01)$. As demonstrated in Fig. 6B, suppression of miR-590-3p by treatment with miR-590-3p inhibitor resulted in markedly decreased cell viability; however, these effects were reversed by the transfection of LRIG1 siRNA. Colony formation capacity was also significantly decreased in the cells transfected with the miR-590-3p inhibitor + scramble siRNA following irradiation, compared with controls (Fig. $6 \mathrm{C} ; \mathrm{P}<0.05$ at $2 \mathrm{~Gy} ; \mathrm{P}<0.01$ at 4 , 6 and $8 \mathrm{~Gy})$. These effects were significantly reversed in the miR-590-3p inhibitor + LRIG1 siRNA group (Fig. 6C; $\mathrm{P}<0.05$ at $2 \mathrm{~Gy} ; \mathrm{P}<0.01$ at 4, 6 and $8 \mathrm{~Gy}$ ). The cell apoptosis rate were significantly different between the miR-590-3p inhibitor + scramble siRNA group and the miR-590-3p inhibitor + LRIG1 siRNA group (Fig. 6D; $\mathrm{P}<0.01$ ).

\section{Discussion}

In the present study, it was initially demonstrated that miR-590-3p was upregulated in the human glioma tissues, and its expression level was higher in high grade than in low grade gliomas. These data suggested that miR-590-3p may contribute to the initiation and development of human gliomas.

Radiotherapy is essential for the treatment of $>30 \%$ of newly diagnosed cancer patients (25). Various miRNAs have been demonstrated to be associated with the radiosensitivity of human glioma cells, such as miR-181a, miR-124 and miR-26a (26-30). The present results indicate that the expression level of miR-590-3p was higher in the radioresistant human glioblastoma cells than that in the parental glioblastoma cells. In vitro experiments were subsequently performed to elucidate the role of miR-590-3p in the radiosensitivity of glioblastoma cells. It was demonstrated that downregulation of miR-590-3p enhanced the radiosensitivity of the radioresistant human glioblastoma cells U251R, as demonstrated by suppressed cell viability, decreased colony formation capacity, and increased cell apoptosis rate. These results indicated that miR-590-3p decreases radiation sensitivity of glioblastoma cells.

LRIG1 is a transmembrane protein that functions as a tumor suppressor in various human cancer cell types (18-20). LRIG1 downregulation has been implicated to be associated with a poor prognosis of patients with renal cell carcinoma or ocular surface squamous neoplasia $(31,32)$. Previous studies have indicated that LRIG1 was frequently decreased in gliomas (21), and the expression level of LRIG1 is significantly correlated with the malignancy of glioma $(21,33)$. It has also been reported that upregulation of LRIG1 expression suppresses malignant glioma cell growth and induces cell apoptosis (21,34-36), whereas downregulation of LRIG1 expression promotes the proliferation and aggressive properties of glioma cells $(37,38)$. Furthermore, previous studies have suggested that LRIG1 is associated with the regulation of chemosensitivity of human cancer cells $(39,40)$. It has been elucidated that LRIG1 sensitizes glioma cells to cisplatin and temozolomide (22,41-43). Recently, Yang et al (22) reported that LRIG1 expression was associated with the radiosensitivity of human glioblastoma cells, and LRIG1 overexpression enhances the radiosensitivity of radioresistant human glioblastoma U251 cells. Consistent with these findings, the present study demonstrated that LRIG1 was downregulated in radioresistant human glioblastoma cells. Furthermore, the luciferase reporter assay demonstrated that LRIG1 was a direct target of miR-590-3p. The effect of miR-590-3p suppression on cell viability, colony formation capacity and cell apoptosis rate was attenuated by the knockdown of LRIG1 in U251R cells. These results suggested that LRIG1 is able to mediate the effect of miR-590-3p on the radiosensitivity of human glioblastoma cells.

In conclusion, the present study identified miR-590-3p as a potential target of radioresistance in human gliomas, and demonstrated that LRIG1 was associated with mediating the effect of miR-590-3p on the radiosensitivity of human glioblastoma cells. These findings may improve the understanding of the association between miRNAs and radiosensitivity in gliomas, and may provide potential therapeutic strategies to prevent radioresistance.

\section{References}

1. Dolecek TA, Propp JM, Stroup NE and Kruchko C: CBTRUS statistical report: Primary brain and central nervous system tumors diagnosed in the United States in 2005-2009. Neuro Oncol 14 (Suppl 5): v1-v49, 2012.

2. Mihailović G, Marković M, Zivković N, Mihailović G, Marković M, Berisavac I and Spaić M: Epidemiological features of brain tumors. Srp Arh Celok Lek 141: 823-829, 2013 (In Serbian).

3. Stupp R, Mason WP, van den Bent MJ, Weller M, Fisher B, Taphoorn MJ, Belanger K, Brandes AA, Marosi C, Bogdahn U, et al: Radiotherapy plus concomitant and adjuvant temozolomide for glioblastoma. New Engl J Med 352: 987-996, 2005.

4. Wang $\mathrm{Y}$ and Jiang T: Understanding high grade glioma: Molecular mechanism, therapy and comprehensive management. Cancer Lett 331: 139-146, 2013.

5. Carlsson SK, Brothers SP and Wahlestedt C: Emerging treatment strategies for glioblastoma multiforme. EMBO Mol Med 6: 1359-1370, 2014.

6. Omuro A and DeAngelis LM: Glioblastoma and other malignant gliomasa: Clinical review. JAMA 310: 1842-1850, 2013.

7. Van Meir EG, Hadjipanayis CG, Norden AD, Shu HK, Wen PY and Olson JJ: Exciting new advances in neuro-oncology: The avenue to a cure for malignant glioma. CA Cancer J Clin 60: 166-193, 2010.

8. Ohgaki H, Dessen P, Jourde B, Horstmann S, Nishikawa T, Di Patre PL, Burkhard C, Schüler D, Probst-Hensch NM, Maiorka PC, et al: Genetic pathways to glioblastoma: A population-based study. Cancer Res 64: 6892-6899, 2004.

9. Atkins RJ, Ng W, Stylli SS, Hovens CM and Kaye AH: Repair mechanisms help glioblastoma resist treatment. J Clin Neurosci 22: 14-20, 2015.

10. Ambros V: The functions of animal microRNAs. Nature 431: 350-355, 2004.

11. Bartel DP: MicroRNAs: Genomics, biogenesis, mechanism and function. Cell 116: 281-297, 2004.

12. Calin GA, Sevignani C, Dumitru CD, Hyslop T, Noch E, Yendamuri S, Shimizu M, Rattan S, Bullrich F, Negrini M and Croce CM: Human microRNA genes are frequently located at fragile sites and genomic regions involved in cancers. Proc Natl Acad Sci USA 101: 2999-3004, 2004.

13. Sevignani C, Calin GA, Nnadi SC, Shimizu M, Davuluri RV, Hyslop T, Demant P, Croce CM and Siracusa LD: MicroRNA genes are frequently located near mouse cancer susceptibility loci. Proc Natl Acad Sci USA 104: 8017-8022, 2007. 
14. Miranda PJ, Vimalraj S and Selvamurugan N: A feedback expression of microRNA-590 and activating transcription factor-3 in human breastcancer cells. Int J Biol Macromol 72: 145-150, 2015

15. Chu Y, Ouyang Y, Wang F, Zheng A, Bai L, Han L, Chen Y and Wang H: MicroRNA-590 promotes cervical cancer cell growth and invasion by targeting CHL1. J Cell Biochem 115: 847-853, 2014.

16. Xiao X, Tang C, Xiao S, Fu C and Yu P: Enhancement of proliferation and invasion by MicroRNA-590-5p via targeting PBRM1 in clear cell renal carcinoma cells. Oncol Res 20: 537-544, 2013.

17. Yang H,Zheng W, Zhao W, Guan C and An J: Roles of miR-590-5p and miR-590-3p in the development of hepatocellular carcinoma. Nan Fang Yi Ke Da Xue Xue Bao 33: 804-811, 2013 (In Chinese).

18. Yokdang N, Hatakeyama J, Wald JH, Simion C, Tellez JD, Chang DZ, Swamynathan MM, Chen M, Murphy WJ, Carraway Iii KL and Sweeney C: LRIG1 opposes epithelial-tomesenchymal transition and inhibits invasion of basal-like breast cancer cells. Oncogene 35: 2932-2947, 2016.

19. Kou C, Zhou T, Han X, Zhuang H and Qian H: LRIG1, a 3p tumor suppressor, represses EGFR signaling and is a nove epigenetic silenced gene in colorectal cancer. Biochem Biophys Res Commun 464: 519-525, 2015.

20. Sheu JJ, Lee CC, Hua CH, Li CI, Lai MT, Lee SC, Cheng J, Chen CM, Chan C, Chao SC, et al: LRIG1 modulates aggressiveness of head and neck cancers by regulating EGFR-MAPK-SPHK1 signaling and extracellular matrix remodeling. Oncogene 33: $1375-1384,2014$

21. Ye F, Gao Q, Xu T, Zeng L, Ou Y, Mao F, Wang H, He Y, Wang B, Yang Z, et al: Upregulation of LRIG1 suppresses malignant glioma cell growth by attenuating EGFR activity. J Neurooncol 94: 183-194, 2009.

22. Yang JA, Liu BH, Shao LM, Guo ZT, Yang Q, Wu LQ, Ji BW, Zhu XN, Zhang SQ, Li CJ and Chen QX: LRIG1 enhances the radiosensitivity of radioresistant human glioblastoma U251 cells via attenuation of the EGFR/Akt signaling pathway. Int J Clin Exp Pathol 8: 3580-3590, 2015.

23. Louis DN, Ohgaki H, Wiestler OD, Cavenee WK, Burger PC, Jouvet A, Scheithauer BW and Kleihues P: The 2007 WHO classification of tumours of the central nervous system. Acta Neuropathol 114: 97-109, 2007.

24. Livak KJ and Schmittgen TD: Analysis of relative gene expression data using real-tie quantitative PCR and the 2(-Delta Delta C(T)) Method. Methods 25: 402-408, 2001.

25 . One in three newly diagnosed cancer patients now receives radiation therapy. Oncology (Williston Park) 10: 1776, 1996.

26. Chen G, Zhu W, Shi D, Lv L, Zhang C, Liu P and Hu W: MicroRNA-181a sensitizes human malignant glioma U87MG cells to radiation by targeting Bcl-2. Oncol Rep 23: 997-1003, 2010.

27. Deng X, Ma L, Wu M, Zhang G, Jin C, Guo Y and Liu R: miR-124 radiosensitizes human glioma cells by targeting CDK4. J Neurooncol 114: 263-274, 2013.

28. Guo P, Lan J, Ge J, Nie Q, Guo L, Qiu Y and Mao Q: MiR-26a enhances the radiosensitivity of glioblastoma multiforme cells through targeting of ataxia-telangiectasia mutated. Exp Cell Res 320: 200-208, 2014.

29. Li W, Guo F, Wang P, Hong $S$ and Zhang C: miR-221/222 confers radioresistance in glioblastoma cells through activating Akt independent of PTEN status. Curr Mol Med 14: 185-195, 2014.

30. Upraity S, Kazi S, Padul V and Shirsat NV: MiR-224 expression increases radiation sensitivity of glioblastoma cells. Biochem Biophys Res Commun 448: 225-230, 2014.
31. Thomasson M, Hedman H, Guo D, Ljungberg B and Henriksson R: LRIG1 and epidermal growth factor receptor in renal cell carcinoma: A quantitative RT-PCR and immunohistochemical analysis. Brit J Cancer 89: 1285-1289, 2003.

32. Nagata M, Nakamura T, Sotozono $\mathrm{C}$, Inatomi T, Yokoi $\mathrm{N}$ and Kinoshita S: LRIG1 as a potential novel marker for neoplastic transformation in ocular surface squamous neoplasia. PLoS One 9: e93164, 2014.

33. Guo D, Nilsson J, Haapasalo H, Raheem O, Bergenheim T, Hedman $\mathrm{H}$ and Henriksson R: Perinuclear leucine-rich repeats and immunoglobulin-like domain proteins (LRIG1-3) as prognostic indicators in astrocytic tumors. Acta Neuropathol 111: 238-246, 2006

34. Johansson M, Oudin A, Tiemann K, Bernard A, Golebiewska A, Keunen O, Fack F, Stieber D, Wang B, Hedman H and Niclou SP: The soluble form of the tumor suppressor Lrig1 potently inhibits in vivo glioma growth irrespective of EGF receptor status. Neuro Oncol 15: 1200-1211, 2013.

35. Mao F, Wang B, Xiao Q, Xi G, Sun W, Zhang H, Ye F, Wan F, Guo D, Lei T and Chen X: A role for LRIG1 in the regulation of malignant glioma aggressiveness. Int J Oncol 42: 1081-1087, 2013.

36. Ye F, Guo DS, Niu HQ, Tao SZ, Ou YB, Lu YP and Lei T: Molecular mechanism of LRIG1 cDNA-induced apoptosis in human glioma cell line H4. Ai Zheng 23: 1149-1154, 2004 (In Chinese).

37. Xie R, Yang H, Xiao Q, Mao F, Zhang S, Ye F, Wan F, Wang B, Lei T and Guo D: Downregulation of LRIG1 expression by RNA interference promotes the aggressive properties ofglioma cells via EGFR/Akt/c-Myc activation. Oncol Rep 29: 177-184, 2013.

38. Mao F, Wang B, Xi G, Sun W, Zhang H, Ye F, Guo D and Lei T: Effects of RNAi-mediated gene silencing of LRIG1 on proliferation and invasion of glioma cells. J Huazhong Univ Sci Technolog Med Sci 32: 227-232, 2012.

39. Wu X, Hedman H, Bergqvist M, Bergström S, Henriksson R, Gullbo J, Lennartsson J, Hesselius P and Ekman S: Expression of EGFR and LRIG proteins in oesophageal carcinoma with emphasis on patient survival and cellular chemosensitivity. Acta Oncol 51: 69-76, 2012

40. Sheu JJ, Lee CC, Hua CH, Li CI, Lai MT, Lee SC, Cheng J, Chen CM, Chan C, Chao SC, et al: LRIG1 modulates aggressiveness of head and neck cancers by regulating EGFR-MAPK-SPHK1 signaling and extracellular matrix remodeling. Oncogene 33: 1375-1384, 2013

41. Guo Z, Chen Q, Liu B, Tian D, Zhang S and Li M: LRIG1 enhances chemosensitivity by modulating BCL-2 expression and receptor tyrosine kinase signaling in glioma cells. Yonsei Med J 55: 1196-1205, 2014

42. Qi XC, Xie DJ, Yan QF, Wang YR, Zhu YX, Qian C and Yang SX: LRIG1 dictates the chemo-sensitivity of temozolomide (TMZ) in U251 glioblastoma cells via down-regulation of EGFR/topoisomerase-2/Bcl-2. Biochem Biophys Res Commun 437: 565-572, 2013.

43. Wang X, Xiao Q, Xing X, Tian C, Zhang H, Ye F, Wan F, Wang B, Guo D and Lei T: LRIG1 enhances cisplatin sensitivity of glioma cell lines. Oncol Res 20: 205-211, 2012. 